\title{
Ocular sequelae of preterm birth and their relation to ultrasound evidence of cerebral damage
}

\author{
JOHN HUNGERFORD, ${ }^{* 1}$ ANN STEWART, ${ }^{2}$ AND PETER HOPE ${ }^{3}$
}

From the 'Department of Ophthalmology, University College Hospital, London; the ${ }^{2}$ Department of Obstetrics and Paediatrics University College London School of Medicine; and the ${ }^{3}$ Department of Paediatrics, University College London School of Medicine

SUMmaRY The eyes of 177 very preterm (<33 weeks' gestation) infants, born between 1979 and 1982 and admitted to a neonatal intensive care unit, were examined as part of an ongoing follow-up study of neurodevelopmental outcome. Ocular pathology was diagnosed in $37(21 \%)$ of the 177 infants: $14(8 \%)$ had retinopathy of prematurity (ROP) - progressive in three-and nine $(5 \%)$ infants had delayed visual maturation (DVM). The ocular pathology was permanent in $26(15 \%)$ of the 177 infants. Refractive errors were the commonest problem and accounted for permanent sequelae in eight of the 14 infants with ROP and two of the nine with DVM. The presence or absence of ROP was related to a wide range of prospectively coded perinatal variables and to the results of routine neonatal ultrasound brain scans and neurodevelopmental follow-up assessments made in the first 18 months of life. As in previous studies, infants with ROP were of shorter gestation, lower birth weight, and required oxygen therapy for longer than unaffected infants, but the condition was only weakly associated with other indices of respiratory illness. In contrast, ROP was strongly associated with evidence of brain damage, often consistent with hypoxic ischaemic injury. We conclude that an underlying lesion in ROP may be hypoxic ischaemic damage to the retinal circulation.

Defective vision has been reported frequently as a cause of permanent handicap in surviving preterm infants.' The impairment described has usually been due to retrolental fibroplasia, more recently termed retinopathy of prematurity (ROP), ${ }^{2}$ and this condition remains the only visual disorder almost exclusively related to the perinatal period. ${ }^{3}$ Refractive error, ${ }^{4}$ strabismus, ${ }^{56}$ and more recently amblyopia ${ }^{7}$ and delayed visual maturation (DVM) ${ }^{8}$ have also been reported in association with preterm birth, though these conditions may be encountered in infants born after a normal period of gestation.

Changing trends in the prevalence of individual visual problems have been reported.' ${ }^{\prime}$ For example, there was a substantial fall in the proportion of very low birth weight (VLBW $<1500 \mathrm{~g}$ ) infants who were blind because of ROP in the years following the

*Present address: Moorfields Eye Hospital, City Road, London EC1V 2PD.

Correspondence to Dr Ann Stewart, Department of Paediatrics, The Rayne Institute, 5 University Street, London WC1E 6JJ. recognition of its association with oxygen therapy in the 1950s. But early hopes that ROP might be eliminated by careful attention to the monitoring of arterial blood gas tensions during oxygen therapy ${ }^{9}$ have not been fulfilled..$^{10-12}$ Concern has recently been expressed that, despite the introduction of improved techniques for continuous monitoring during oxygen therapy, the prevalence of ROP arı. infants may be rising again. ${ }^{210-14}$ The purpose of this report is to describe the visual status at follow-up of 177 very preterm infants prospectively studied over a period of $3 \frac{1}{2}$ years, and to explore the pathogenesis of ROP in this population of infants.

\section{Material and methods}

Infants studied. Two hundred and seventy-seven infants born before 33 weeks of gestation were admitted to the Neonatal Unit of University College Hospital (UCH), London, between January 1979 and June 1982. One hundred and ninety-nine of these infants survived the neonatal period, including 108 
who were born in UCH and 91 who were transferred from other centres within one week of birth. The eyes of 177 of the 199 surviving infants were examined, and these 177 infants are the subject of this report. Of the remainder, 22 infants failed to keep appointments, five moved out of the country, and two moved to another city shortly after discharge from hospital.

Clinical management. Methods of management of the infants, many of whom were seriously ill, were in general as described previously. ${ }^{15}$ Particular attention was paid to the monitoring of blood gases by the use of continuous intra-arterial ${ }^{16}$ or transcutaneous techniques. ${ }^{17}$

Ultrasound. The brains of all the infants were scanned with ultrasound, daily for the first week of life and thereafter once or twice weekly until the infants were discharged or died, as described elsewhere. ${ }^{18}$

Ophthalmological examinations. Where possible, a fundus examination was performed in the neonatal unit about two weeks after oxygen therapy ceased. All infants were then examined shortly after discharge from hospital in a special follow-up clinic as part of an ongoing study of outcome in very preterm infants. At this examination the ability to fixate on a large bright object was first assessed and the pupil responses were noted. Disorders of ocular motility were characterised, and where possible the presence or absence of amblyopia was assessed by the Catford drum. ${ }^{19}$ Mydriasis and cycloplegia were then produced with $0 \cdot 5 \%$ cyclopentolate drops. Children with heavily pigmented irides required additional $2.5 \%$ phenylephrine drops to achieve adequate pupil dilatation. The refraction was determined objectively by retinoscopy prior to fundus examination by indirect ophthalmoscopy. Any degree of myopia was regarded as abnormal. Hypermetropia and astigmatism of small degree are physiological and were not considered abnormal unless greater than 1.0 or 0.5 dioptre respectively. Fundus examination by indirect ophthalmoscopy confirmed the presence or absence of ROP. When diagnosed, ROP was classified according to five stages of development as described by Keith. ${ }^{2121}$

DVM was diagnosed when the fixation reflex could not be elicited in the alert, wakeful child, when both eyes were structurally normal, and when there was no evidence of roving eye movements or abnormality of the pupil responses to light. ${ }^{22}$

Follow up. Perinatal details were recorded prospectively, coded, and stored for later computer analysis. At follow-up in addition to ophthalmological examinations the investigations included neurological, otological, audiological, and developmental assessments in the first 18 months of life. As the children grew older, language, cognitive functioning, and motor skills were assessed. Details of the methods employed have been described previously. ${ }^{18}$

\section{Results}

The eyes of 84 of the 177 infants were first examined in the Neonatal Unit. They were examined again together with the eyes of the remaining 93 infants in the follow-up clinic until a maximum age ranging from 3 to 40 months (median 18 months), after correction for preterm birth. One of the 22 infants who was not examined died aged 24 months. This infant was profoundly abnormal, with cerebral palsy and overall developmental delay, including absent visual responses. The remaining 21 infants were seen in our own or other follow-up clinics as they grew older and were considered on clinical grounds to have satisfactory vision.

Fourteen $(8 \%)$ of the 177 infants whose eyes were examined had fundus signs of ROP, including 9 $(11 \%)$ of the 84 infants first examined in the Neonatal Unit. The signs were bilateral in all 14, though not necessarily symmetrical. In 11 infants ROP did not progress beyond stage I-II. None of these 11 received active treatment and none developed cicatricial retinopathy. The condition resolved spontaneously in four with no ocular sequelae. Six of the other seven infants developed myopia, associated with a convergent squint in one. The seventh child had a convergent squint only. Three infants developed stage III ROP. One infant, with stage IIIb disease, had cryotherapy abroad with a good visual result and no evidence of progressive cicatricial change. The other two infants with stage III disease were not treated. Both developed low myopia, associated in one of them with a divergent squint and delayed visual maturation. Neither infant developed cicatricial retinopathy, and both had satisfactory vision after correction of the refractive error. Details of all 14 affected infants are shown in Table 1.

Refractive error. Almost all the 84 infants examined before discharge from hospital were myopic ( -0.50 DS to $-7.0 \mathrm{DS})$ during the neonatal period. By contrast just $17(6 \%)$ of the total of 177 infants in the study had errors of refraction which persisted beyond this period, including eight with ROP.

Amblyopia and disorders of ocular motility. Twelve $(7 \%)$ infants had amblyopia or abnormal ocular movements. In all instances the defect was first detected in the outpatient clinic more than three months after birth.

Delayed visual maturation. Nine $(5 \%)$ infants showed no visual awareness nor made following responses to a bright light at the first outpatient examination, aged 1 to 12 weeks (after correction for 
Table 1 Ophthalmological, neonatal, and neurodevelopmental diagnoses in 14 infants with ROP and nine with DVM

\begin{tabular}{|c|c|c|c|c|c|c|c|c|c|c|}
\hline$R O P$ & $D V M$ & $\begin{array}{l}\text { Refractive } \\
\text { error }\end{array}$ & Squint & $\begin{array}{l}\text { Gest } \\
(w k)\end{array}$ & $\begin{array}{l}\text { Birth } \\
\text { weight }(g)\end{array}$ & $H M D$ & Apnoea & $M V$ & $U S$ & $\begin{array}{l}\text { Neurodevelop- } \\
\text { mental disorder }\end{array}$ \\
\hline+ & & & & 24 & 842 & + & + & + & PVH & Minor \\
\hline+ & & + & & 25 & 845 & & + & + & PVH & Minor \\
\hline+ & & & & 25 & 955 & + & + & + & PVH+ VD* & Major \\
\hline \multirow[t]{2}{*}{ IIIb } & & & & 25 & 990 & + & + & + & PVH+VD* & Major \\
\hline & + & & & 26 & 910 & + & + & + & PVH & \\
\hline III & & + & & 26 & 938 & + & + & + & PVH+VD* & Major \\
\hline+ & + & & & 27 & 680 & & + & + & PVH+VD & Major \\
\hline+ & & + & & 27 & 1165 & + & + & + & $\mathrm{PVH}$ & \\
\hline+ & & + & + & 28 & 968 & + & + & + & Atrophy & Minor \\
\hline \multirow[t]{2}{*}{+} & & + & & 28 & 1114 & + & + & + & PVH & \\
\hline & + & & & 28 & 1278 & & & + & PVH & Major (died) \\
\hline+ & & & & 29 & 940 & + & + & + & & Major \\
\hline \multirow[t]{2}{*}{ III } & + & + & + & 29 & 1020 & + & + & + & PHH & Major \\
\hline & + & & & 30 & 1277 & + & & + & & \\
\hline \multirow[t]{3}{*}{+} & & + & & 30 & 1400 & + & + & + & $\mathrm{PHH}+$ atrophy & Major \\
\hline & + & & & 30 & 1484 & + & + & + & PVH+atrophy & Major (died) \\
\hline & + & & & 31 & 1060 & & + & + & & \\
\hline \multirow[t]{2}{*}{+} & & & + & 31 & 1651 & & & & Atrophy (on CT) & Major \\
\hline & + & + & + & 31 & 1735 & & + & & $\begin{array}{l}\text { PVH+VD* } \\
\text { (atrophy on CT) }\end{array}$ & Major \\
\hline \multirow[t]{2}{*}{+} & & + & & 31 & 1740 & + & & + & PVH & \\
\hline & + & & & 32 & 1205 & + & & + & PVH & \\
\hline
\end{tabular}

$\mathrm{HMD}=$ hyaline membrane disease; $\mathrm{MV}=$ mechanical ventilation; $\mathrm{US}=$ ultrasound.

Neurodevelopmental disorders: major=disabling conditions including cerebral palsy, sensory neural hearing loss, and overall developmental delay; minor=abnormalities of tone and reflexes without functional disability. ${ }^{18}$

PVH = periventricular haemorrhage: haemorrhage arising in the region of the germinal layer \pm intraventricular haemorrhage. ${ }^{18}$

$\mathrm{PHH}=$ posthaemorrhagic hydrocephalus. ${ }^{18}$

$\mathrm{VD}=$ ventricular dilatation of lesser degree than $\mathrm{PHH} .{ }^{1836}$

$\mathrm{VD}^{*}=$ persistent ventricular dilatation.

Atrophy $=$ local or generalised loss of brain tissue. ${ }^{1 \times 36}$ For detailed definition of ultrasound lesions, see Stewart et al $^{18}{ }^{36}$

$\mathrm{CT}=$ computerised tomography.

preterm birth). Pupillary reaction to light was normal in all nine. A diagnosis of DVM was made. Details of these infants are included in Table 1 . Visual responses were eventually detected among the seven surviving infants at a median age of six months (range three to nine months) after correction for preterm birth. No responses were detected in the two infants who died aged five months of corrected age.

Prevalence and pathogenesis. Thirty-seven (21\%) of the 177 infants studied had ocular pathology at some stage of the investigation, including seven with multiple problems. In 11 of these 37 infants ROP or DVM alone was diagnosed, which resolved completely so that no permanent ocular sequelae could be detected. Thus only $26(15 \%)$ of the 177 infants had permanent visual defects.

In order to explore the relationship between perinatal factors and ocular pathology the characteristics of the infants, neonatal investigations, illnesses and treatments, ultrasound findings, and neurodevelopmental status at follow-up were compared between unaffected infants and those with ROP, DVM, or refractive errors, amblyopia, and disorders of ocular motility not associated with ROP. Infants with ROP differed significantly from unaffected infants in several respects, shown in Table 2 . For example, they were of lower birth weight $(p<0.01)$ and of shorter gestation $(p<0 \cdot 005)$. They were more likely to have apnoeic spells $(p<0.05)$, hypertensive episodes $(p<0.025)$, periventricular haemorrhage $(p<0.025)$, ultrasound or computerised tomographic evidence suggestive of hypoxic ischaem is brain injury $(p<0.01)$, to require prolonged treatment with oxygen $(p<0.0005)$ or treatment with mechanical ventilation $(p<0 \cdot 05)$, and to have neurodevelopmental abnormalities $(p<0.0005)$ as they grew older. In contrast none of these differences were found among any of the other groups when compared with their unaffected peers.

\section{Discussion}

PREVALENCE OF OCULAR PATHOLOGY

The prevalence of permanent ocular pathology diagnosed by a median age of 18 (range 3-40) months in this group of very preterm infants was $15 \%(26 / 177)$. 
Table 2 Relationship of ROP and DVM with perinatal factors, ultrasound findings, and neurodevelopmental status at follow-up at ages 12-18 months

\begin{tabular}{|c|c|c|c|c|}
\hline & \multicolumn{2}{|l|}{$R O P$} & \multicolumn{2}{|l|}{$D V M$} \\
\hline & No, $n=163$ & Yes, $n=14(n=9)^{*}$ & No, $n=168$ & Yes, $n=9$ \\
\hline $\begin{array}{l}\text { Birth weight, g, median } \\
\text { (range) }\end{array}$ & $\begin{array}{l}1350 \\
(6(0)-25(0))\end{array}$ & $\begin{array}{l}1089+++ \\
(680-1740)\end{array}$ & $\begin{array}{l}1337 \\
(6(0)-25(x))\end{array}$ & $\begin{array}{l}1183 \\
(68(1)-1735)\end{array}$ \\
\hline $\begin{array}{l}\text { Gestation, weeks, median } \\
\text { (range) }\end{array}$ & $\begin{array}{c}30 \\
(24-32)\end{array}$ & $\begin{array}{l}28++++ \\
(24-32)\end{array}$ & $\begin{array}{l}30 \\
(24-32)\end{array}$ & $\begin{array}{c}30) \\
(26-32)\end{array}$ \\
\hline Boys/girls & $9(0 / 73$ & $8 / 6$ & $95 / 73$ & $3 / 6$ \\
\hline Vaginal delivery & 92 & 12 & 97 & 7 \\
\hline cacsarian scction & 71 & 2 & 71 & 2 \\
\hline Apgar $\leqslant 3,1 \mathrm{~min}:$ & 45 & 5 & 46 & 4 \\
\hline $\begin{array}{l}\text { Basc deficit } \geqslant 15 \mathrm{mmol} / \mathrm{l}, \\
\leqslant 2 \text { hours of age }\end{array}$ & 3 & 2 & 4 & 1 \\
\hline Hyaline membrane disease & 88 & 10 & 94 & 4 \\
\hline Apnocic spells & 86 & $12(7)+$ & 92 & 6 \\
\hline Mechanical ventilation & 97 & $13(8)+$ & 102 & 8 \\
\hline Oxygen therapy & 143 & $13(9)$ & 147 & 9 \\
\hline $\begin{array}{l}\text { Duration of oxygen therapy, } \\
\text { days, median (rangc) }\end{array}$ & $\begin{array}{c}9 \\
(1-105)\end{array}$ & $\begin{array}{l}53+++++ \\
(1-1(6)\end{array}$ & $\begin{array}{l}13 \\
(1-106)\end{array}$ & $\begin{array}{l}22 \\
(1-81)\end{array}$ \\
\hline Hypertensive episodes $\dagger$ & 70 & $11++$ & 74 & 7 \\
\hline Scrum bilirubin $\geqslant 170 \mu \mathrm{mol} / 1$ & 88 & 9 & 94 & 3 \\
\hline Periventricular hacmorrhage $\ddagger$ & 66 & $11(7)++$ & 70) & 7 \\
\hline $\begin{array}{l}\text { Ventricular dilatation, hydrocephalus, } \\
\text { atrophy } \ddagger\end{array}$ & 29 & $7(4)++$ & 32 & 4 \\
\hline Hypoxic ischacmic injury & 12 & $5(3)++++$ & 15 & 2 \\
\hline Neurodevclopmental disorders $\ddagger$ & 29 & $11(6)+++++$ & 37 & 5 \\
\hline
\end{tabular}

*Number of infants with permanent sequelac.

†Recorded cpisodes of systolic blood pressure $>2$ standard deviations above the mean for gestation. ${ }^{37}$ $\ddagger$ Sec footnote to Table 1 for definitions. ${ }^{1 \times 36}$

$t=p<() \cdot 05 . \quad++=p<0.025 . \quad+++=p<0.01 . \quad++++=p<() \cdot(0) 5 . \quad+++++=p<(0 .(0)(0) 5$.

Refractive errors $(17 / 177,10 \%)$ were the most common problem and accounted for the persisting pathology in infants in whom ROP $(8 / 14)$ or DVM (2/9) was diagnosed in the early months of life. The prevalence of permanent ocular pathology due to ROP was $5 \%(9 / 177)$, and three of these infants $(1.6 \%)$ had progressive disease (stage III-IIIb ROP). None of the nine were blind. These values are much lower than those reported from other centres among comparable infants. ${ }^{23}{ }^{24}$ More than half $(8 / 14$, $57 \%$ ) of the affected infants weighed $<1000 \mathrm{~g}$ (extremely low birth weight, ELBW) and half (7/14) were born before 28 weeks of gestation. The prevalence of sequelae in these infants was $10 \%(3 / 31)$ and $9 \%(3 / 34)$ respectively, similar to that reported by Yu et al. ${ }^{25}$ among ELBW infants. When refractive error, squint, or DVM did occur in the VLBW infants in this study, it was usually in association with ROP - an association which probably explains the high prevalence of both squint and refractive error reported among VLBW in the past. ${ }^{5}$ Surveillance began in the Neonatal Unit in only $84(47 \%)$ of the infants in this study, specially chosen because they were of particularly low birth weight and very sick. The prevalence of ROP in these especially vulnerable infants was $11 \%(9 / 84)$. Although it is possible that minor degrees of ROP might have resolved spontaneously before surveillance began in the outpatient clinic among the remaining 93 (53\%) infants, we believe that this is unlikely, since the prevalence $(5 / 93,5 \%)$ among these infants did not differ significantly from that among the infants first examined before leaving the Neonatal Unit $\left(\chi^{2}=1 \cdot 07, \mathrm{df}=1\right)$. Thus there is no evidence from this study of very preterm infants cared for in a modern neonatal intensive care unit of an increase in the prevalence of ROP or its sequelae in spite of greatly improved survival rates. ${ }^{26}$

\section{PATHOGENESIS OF ROP AND DVM}

In this study, as in all previous ones, ${ }^{1}$ ROP was significantly associated with apnoea of prematurity and treatment with mechanical ventilation. In addition the duration of oxygen therapy was significantly longer among the group of infants who had ROP than in those who did not develop the condition; and hypertensive episodes were recorded more frequently among infants who developed ROP than those who did not (Table 2). Nevertheless, although these factors occurred significantly more often or, in the case of oxygen therapy for longer, in the ROPaffected infants when considered as a group, many of 
the infants who did not develop the condition had similar illnesses and treatments; and one infant who developed ROP had neither apnoea nor was treated with oxygen or mechanical ventilation after the first 14 minutes of life when resuscitation was completed. Thus we infer-as have others when considering the results of previous studies' - that no one factor is alone responsible for the condition but rather a combination of factors or circumstances.

More striking than the association of ROP with respiratory illness and its treatment was the association with other neurodevelopmental disorders at follow-up (11/14). Others have recently reported a similar excess of neurodevelopmental morbidity among infants with ROP. ${ }^{27}$ Although it is reasonable to consider that the infants who have neurodevelopmental abnormalities at follow-up were the sickest ones who needed the most oxygen for longest, and were therefore the most liable to its toxic effects, there is an alternative interpretation.

The brains of all the infants in this study were scanned with ultrasound in the first days of life. Lesions were detected in $12(86 \%)$ of the 14 ROPaffected infants, including eight $(89 \%)$ of the nine with permanent ocular sequelae. In contrast, lesions were detected in the brains of less than half $(71 / 163$; $44 \%$ ) of the 163 infants in whom ROP was not diagnosed (Table 2). The lesion in five of the 12 infants with ROP, including two of the three infants with stage III disease, was considered to be consistent with hypoxic ischaemic injury. Likewise seven of the nine infants with DVM had periventricular haemorrhage (PVH); two had additional ultrasound evidence consistent with hypoxic ischaemic brain injury, and five had neurodevelopmental disorders at follow-up. Hypoxic ischaemic lesions diagnosed with ultrasound are known to be closely associated with neurodevelopmental disorders. ${ }^{18}$ Thus there is strong evidence of brain damage, often of hypoxic ischaemic origin, in the majority of the infants with ROP, including all three with stage III disease, and to a lesser extent in infants with DVM. This suggests that the same set of circumstances that cause hypoxic ischaemic damage to the immature brain may also cause ROP and possibly DVM.

Procianoy et al..$^{28}$ have previously reported an association between PVH and ROP. As in our study, this association was stronger than that between ROP (all cases as well as those with sequelae) and respiratory illness or treatment with oxygen. These authors pointed out that there are good theoretical reasons for such an association. Both conditions are vascular circulatory disorders affecting immature blood vessels, and both the ocular and cerebral circulations share a common origin, the internal carotid artery. Factors which regulate cerebral blood flow act in similar ways on the regulation of the retinal circulation,,$^{29.31}$ and several of these factors have been implicated in the aetiology of PVH, notably hypercarbia, asphyxia, and hypoxaemia. ${ }^{3132}$ Bracher et al. ${ }^{33}$ using a photographic technique to observe retinal vessels in newborn infants, noted in asphyxiated infants that the response of retinal arteries to extremes of circulatory oxygen tensions appeared to be abolished. Thus the vessels remained dilated in the presence of high levels of oxygen in the immediate newborn period and constricted in the presence of hypoxaemia and hypotension when the infants were a little older. These are just the circumstances hypothesised by Silverman ${ }^{34}$ as prerequisites for retinal damage, on the basis of the results of animal experiments by Flower et al. ${ }^{35}$

The present study, by combining information from prospective neonatal brain ultrasound scans and detailed neurodevelopmental assessments made throughout the first 12-18 months of life, provides evidence of an association between ROP and brain injury, often of hypoxic ischaemic origin. Our data support proposals that an underlying lesion in ROP may be hypoxic ischaemic damage to the retinal circulation. $^{28}$

Many colleagues helped with this study and we wish to thank them. Special thanks are due to Professor EOR Reynolds for his help and support throughout the study and with the preparation of the manuscript, and to Miss Jan Townsend, who organised our joint clinics which made this study possible.

AS and PH were supported by a grant from the Medical Research Council.

\section{References}

1 Lucey JF, Dangman B. A re-examination of the role of oxygen in retrolental fibroplasia. Pediatrics 1984; 73: 82-96.

2 Payne JW, Patz A. Current status of retrolental fibroplasia. The retinopathy of prematurity. Ann Clin Res 1979; 11: 205-21.

3 Kinsey VE. Cooperative study of retrolental fibroplasia and the use of oxygen. Arch Ophthalmol 1956; 56: 481-543.

4 Fletcher MC, Brandon S. Myopia of prematurity. Am J Ophthalmol 1955; 40: 474-81.

5 Möller DE. Incidence of ocular changes in premature babies. Klin Monatsbl Augenheilkd 1970; 156: 654-oi.

6 Foster RS, Metz HS, Jampolsky A. Strabismus and pseudostrabismus with retrolental fibroplasia. Am J Ophthalmol 1975; 79: $985-9$.

7 Kushner BJ. Strabismus and amblyopia associated with regressed retinopathy of prematurity. Arch Ophthalmol 1982; 100: 256-61.

8 Hoyt CS, Jastrzebski G, Marg E. Delayed visual maturation in infancy. BrJ Ophthalmol 1983; 67: 127-30.

9 Guy LP, Lanman JT, Dancis J. The possibility of total elimination of retrolental fibroplasia by oxygen restriction. Pediatrics 1956: $17:$ :247-9.

10 Gunn TR, Aranda JV, Little J. Incidence of retrolental fibroplasia. Lancet 1978; i: 216-7.

11 Tarkkanen A, Mustonen R. Retrolental fibroplasia: cases seen at the Helsinki University Eyc Hospital 1956-1974. Acta Ophthalmol (Kbl) 1978; 56: 169-78.

12 Phelps DL. Retinopathy of prematurity: an estimate of vision loss in the United States-1979. Pediatrics 1981; 67: 924-6. 
13 DeLeon AS, Elliott JH, Jones DB. The resurgence of retrolental fibroplasia. Pediatr Clin North Am 1970; 17: 309-22.

14 Mousel DK. Retinopathy of prematurity in the intensive care nursery. J Pediatr Ophthalmol Strabismus 1978; 15: 14750 .

15 Reynolds EOR. Neonatal intensive care and the prevention of major handicap. In: Elliott K, O'Connor M, eds. Major mental handicap: methods and costs of prevention. Ciba Foundation Symposium No. 59 (new series). Amsterdam: Elsevier/North Holland, 1978: 77-102.

16 Pollitzer MJ, Soutter LP, Reynolds EOR, Whitehead MD. Continuous monitoring of arterial oxygen tension in infants; four years experience with an intravascular oxygen electrode. Pediatrics 1980 ; 66: 31-6.

17 Pollitzer MJ, Whitehead MD, Reynolds EOR, Delpy D. Effect of electrode temperature and in vivo calibration on accuracy of transcutaneous estimation of arterial oxygen tension in infants. Pediatrics 1980; 65: 515-22.

18 Stewart A, Thorburn RJ, Hope PL, Goldsmith M, Lipscomb AP, Reynolds EOR. Ultrasound appearance of the brain in very preterm infants and neurodevelopmental outcome at 18 months of age. Arch Dis Child 1983; 58: 598-604.

19 Catford GV, Oliver A. A method of visual acuity detection. Proceedings of the second international orthoptic congress. Amsterdam: Excerpta Medica, 1972: 183-7.

20 Keith CG. Retrolental fibroplasia, a new classification of the developing and cicatricial stages. Aust J Ophthalmol 1979; 7: 189-94.

21 Keith CG. Visual outcome and effect of treatment in stage III developing retrolental fibroplasia. Br J Ophthalmol 1982; 66: 446-9.

22 Cole GF, Hungerford J, Jones RB. Delayed visual maturation. Arch Dis Child 1984; 59: 107-10.

23 Kalina RE, Karr DJ. Retrolental fibroplasia: experience over two decades in one institution. Ophthalmology (Rochester) 1982; 89: $91-5$.

24 Shohat M, Reisner SH, Krikler R, Nissenkorn I, Yassur Y, BenSira I. Retinopathy of prematurity: incidence and risk factors. Pediatrics 1983; 72: 159-63.

25 Yu VYH, Hookham DM, Nave JRM. Retrolental fibroplasiacontrolled study of 4 years' experience in a neonatal intensive care unit. Arch Dis Child 1982; 57: 247-52.
26 Stewart A, Reynolds EOR, Lipscomb AP. Outcome for infants of very low birth weight: survey of world literature. Lancet 1981; 1: $1038-41$.

27 Vohr BR, Garcia Coll CT. Increased morbidity in low-birthweight survivors with severe retrolental fibroplasia. J Pediatr 1985; 106: 287-91.

28 Procianoy RS, Garcia-Prats JA, Hittner HM, Adams JM Rudolph AJ. An association between retinopathy of prematurity and intraventricular hacmorrhage in very low birth weight infants. Acta Paediatr Scand 1981; 70: 473-7.

29 Pape KE, Wigglesworth JS. Haemorrhage, ischaemia and the perinatal brain. Clinics in Developmental Medicine No 69-70. Spastics Internation Medical Publications, London: Heinemann, 1979: 39-58.

30 Demant E, Nagahara N, Meyer G. Effects of changes in systemic blood pressure on the electroretinogram of the cat: evidence for retinal autoregulation. Invest Ophthalmol Vis Sci 1982; 23: 683-7.

31 Cook RWI. Factors associated with periventricular haemorrhage in very low birth-weight infants. Arch Dis Child 1981; 56: 425-31.

32 Dykes FD, Lazzara A, Ahmann P, Blumstein B, Schwartz J, Brann AW. Intraventricular haemorrhage: a prospective evaluation of etiopathogenesis. Pediatrics 1980; 66: 42-9.

33 Bracher D, Lotmar E, Bossi E, Vassella F. Fundus photography in neonates, an approach to obtain indirect information on cerebral blood flow. Helv Paediatr Acta 1975; 30: 473-86.

34 Silverman WA. Retinopathy of prematurity: oxygen dogma challenged. Arch Dis Child 1982; 57: 731-3.

35 Flower RW, Blake DA. Retrolental fibroplasia: evidence for a role in the prostaglandin cascade in the pathogenesis of oxygeninduced retinopathy in the newborn beagle. Pediatr Res $1981 ; 15$ : 1293-302.

36 Stewart AL. Assessment of the preterm infant and prognosis. In Beard RW, Sharp F, eds. Preterm labour and its consequences London: Royal College of Obstetricians and Gynaccologists, 1985: 25-36.

37 Versmold HT, Kitterman JA, Phibbs RH, Gregory A. Toolcy WH. Aortic blood pressure during the first 12 hours of life in infants with birthweights 610-4220 g. Pediatrics 1981; 67: 607-13.

Accepted for publication 18 October 1985. 